COMUNICAÇÃO CIENTÍFICA

\title{
GARFAGEM E DIÂMETRO DE PORTA-ENXERTO NA OBTENÇÃO DE MUDAS DE UMBUZEIRO DO ACESSO LARANJA ${ }^{1}$
}

\author{
WIARA DE ASSIS GOMES², REJANE MARIA NUNES MENDONÇA ${ }^{3}$, \\ ELIZIETE PEREIRA DE SOUZA ${ }^{4}$, MARIA ALEXANDRA ESTRELA ${ }^{5}$, VÍTOR E SILVA MELO ${ }^{6}$, \\ SILVANDA DE MELO SILVA ${ }^{7}$, ADAILSON PEREIRA DE SOUZA ${ }^{8}$
}

RESUMO- O objetivo do trabalho foi verificar a eficiência de diferentes métodos de garfagem em umbuzeiro, realizadas sobre dois diâmetros de porta-enxerto. Os tratamentos foram dispostos em delineamento inteiramente casualizado, em esquema fatorial $2 \times 2$, sendo os fatores: diâmetros $(0,5-0,7 \mathrm{~cm}$ e $0,75-1,0$ $\mathrm{cm}$ ) e métodos de garfagem (em fenda cheia e à inglesa simples), com 3 repetições e 8 plantas por parcela. Avaliaram-se o percentual de pegamento dos enxertos, bem como o crescimento das brotações. O método de garfagem à inglês simples mostrou pegamento de enxertos superior à garfagem em fenda cheia. $\mathrm{O}$ maior diâmetro de porta-enxerto possibilitou maior percentual de pegamento da enxertia e maior comprimento e diâmetro das brotações dos enxertos de umbuzeiro.

Termos para indexação: Spondias tuberosa, propagação, porta-enxerto.

\section{GRAFT AND DIAMETER OF STOCK ON OBTAINNING SEEDLINGS OF UMBUZEIRO (Spondias tuberosa) FROM THE ORANGE ACCESS}

\begin{abstract}
The objective of this study was to verify the efficiency of different methods of grafting in umbuzeiro, as well as, to observe the behavior of different diameter of stock. The treatments were arranged in a randomized design in factorial $2 \times 2$ factors, in which the factors were: diameters $(0,5-0,7 \mathrm{~cm}$ and $0,75-$ $1,0 \mathrm{~cm}$ ) and grafting (cleft graft and splice graft), using three repetitions, with eight plants per parcel. The percentage of grafting success and growth of shoots were evaluated. The splice grafting showed higher fixation than the cleft grafting. The largest diameter of the stock allowed a higher percentage of grafting and a greater length and diameter of the graft shoots of umbuzeiro.
\end{abstract}

Index terms: Spondias tuberosa, propagation, rootstock.

O umbuzeiro é uma frutífera nativa da região Nordeste do Brasil, com ocorrência nas regiões Norte e Sudeste, representando fonte de emprego e renda no período da safra, para as populações na área de ocorrência das plantas (ARAÚJO; CASTRO NETO, 2002). Segundo Khan et al. (2003), a Bahia tem-se destacado como maior produtor extrativo de umbuzeiro do Nordeste. Em 2003, o sudeste baiano produziu 1.803,7 t, em uma área média de 509,4 ha (CODEVASF, 2001). Devido ao nível de importância da cultura e ao declínio de produção em decorrência do desmatamento da caatinga, soluções tecnológicas, principalmente em relação a sua obtenção de mudas, são necessárias.
Neste sentido, a propagação sexuada de umbuzeiro tem-se mostrado inviável para a produção de mudas comerciais, pelo longo período juvenil, bem como pela elevada variabilidade com relação aos caracteres relacionados às folhas e frutos (PIRES, 1990). Entretanto, as sementes podem ser utilizadas para a obtenção de porta-enxertos, pela capacidade de formar túberas e armazenar água e substâncias nutritivas, possibilitando o desenvolvimento das plantas em condições de sequeiro. Desta forma, a propagação assexuada de umbuzeiro, pela enxertia, tem-se mostrado eficaz para promover a redução da juvenilidade das plantas, a uniformização do pomar e a padronização da produção, trazendo maior qua-

${ }^{1}$ (Trabalho 113-09). Recebido em: 11-05-2009. Aceito para publicação em: 06-04-2010.

${ }^{2}$ Mestranda em Agronomia, PPGA/CCA/UFPB, wiaradeassisgomes@yahoo.com.br

${ }^{3}$ Profa. Orientadora, Depto, de Fitotecnia e Ciências Ambientais, CCA/UFPB, rejaneufpb@yahoo.com.br

${ }^{4}$ Doutoranda em Agronomia, PPGA/CCA/UFPB

${ }^{5}$ Mestranda em Irrigação e Drenagem, COPEAG/PPEA/UFCG

${ }^{6}$ Mestrando em Agroecossistemas, NEREN/UFS

${ }^{7}$ Profa. Adjunta do DCFS, CCA/UFPB, silvasil@cca.ufpb.br

${ }^{8}$ Prof. Adjunto do DSER, CCA/UFPB. 
lidade e poder de negociação da produção final. A enxertia vem apresentando resultados promissores na produção de mudas de cajazeira, umbu-cajazeira e umbuzeiro (MARTINS; MELO, 2007). No entanto, as matrizes utilizadas para retirada de propágulos são provenientes de propagação seminífera, resultando em elevada variabilidade, que repercute na divergência entre comportamentos para a mesma espécie. Espíndola et al. (2004), pesquisando diâmetro de caule $(04-06 \mathrm{~mm}$ e $07-09 \mathrm{~mm})$ e métodos de enxertia (garfagem em fenda cheia e garfagem à inglesa simples) no umbuzeiro, observaram que a garfagem em fenda cheia e inglês simples apresentaram 100 e $98,5 \%$ de pegamento, respectivamente, com comportamento superior para o maior diâmetro. Araújo e Castro Neto (2002), avaliando o efeito de fatores fisiológicos, época de realização e métodos de enxertia (garfagem em fenda cheia, garfagem à inglesa simples e borbulhia T invertido) em umbuzeiro, concluíram que os teores de carboidratos encontrados na planta-matriz, nas diferentes fases fenológicas, não influenciaram no índice de pegamento, e nos métodos de garfagem.

Contudo, nem todos os trabalhos realizados caracterizam de forma clara o acesso utilizado, o que permite muitas divergências de comportamento quanto ao melhor diâmetro e método de enxertia, a fim de que possa permitir a definição de um protocolo para a produção de mudas comerciais de umbuzeiro.

Diante do exposto, o presente trabalho teve como objetivo avaliar o diâmetro de porta-enxerto e o método de garfagem que proporcionem melhor pegamento e crescimento dos enxertos de umbuzeiro do acesso Laranja.

O ensaio foi realizado no Viveiro de Fruticultura do Centro de Ciências Agrárias da Universidade Federal da Paraíba, entre junho e dezembro de 2006. Os tratamentos foram dispostos em delineamento inteiramente casualizado, com três repetições e 8 plantas por parcela, arranjados em esquema fatorial 2 x 2, com os fatores diâmetro do porta-enxerto $(0,5-0,7 \mathrm{~cm}$ e $0,75-1,0 \mathrm{~cm})$ e métodos de garfagem (garfagem em fenda cheia e à inglês simples).

Os porta-enxertos foram provenientes de sementes coletadas em julho de 2005, colocadas para germinar em sacos de $15 \times 30 \mathrm{~cm}$, contendo substrato composto de areia, terra vegetal e composto orgânico, na proporção de 1:1:1 (v:v:v). Aos 330 dias após o plantio da semente, foi realizada a seleção dos porta-enxertos, mensurando-se, com paquímetro, o diâmetro do caule a $15 \mathrm{~cm}$, altura em que se procedeu a enxertia. Os enxertos foram protegidos contra o dessecamento, por meio de câmara úmida feita com saquinho plástico transparente. O saquinho foi retirado logo após iniciar a brotação. Desde a semeadura para obtenção dos porta-enxertos, até o final do ensaio, as mudas permaneceram sob sombrite com $50 \%$ de luminosidade, sendo irrigadas diariamente.

Os garfos provieram de plantas de "umbularanja", que se encontrava em repouso vegetativo, localizadas no município de Pocinhos, na microrregião do Cariri Paraibano, sendo retirados no dia 31 de maio de 2006. Esses foram preparados segundo os tratamentos, ficando com 10 centímetros de comprimento e, em média, duas gemas.

Avaliou-se o percentual de pegamento dos enxertos aos 45 dias após a enxertia, de acordo com Araújo e Castro Neto (2002). As avaliações quinzenais foram realizadas a fim de acompanhar: o comprimento das brotações dos enxertos, medindose da base ao ápice, com régua milimetrada. Apenas quando as brotações atingiram dois centímetros de comprimento foram incluídas na mensuração. Para medição do crescimento em diâmetro das brotações dos enxertos, tomado a um centímetro da base da brotação, foi utilizado paquímetro.

Os dados foram submetidos à análise de variância com desdobramento do efeito dos tratamentos, segundo sua significância, pelo teste F, a $5 \%$ de probabilidade. Para o efeito quantitativo (tempo), foram realizadas análises de regressão, ajustando o modelo logístico, $\mathrm{Y}=\mathrm{a} /\left(1+\mathrm{e}^{(\mathrm{b}-\mathrm{cX})}\right)$, em que $\mathrm{Y}$ representa a resposta da variável de crescimento no tempo (X); $a$ é a expressão máxima assintótica do crescimento; $b$ é uma constante de integração; e $c$ é a taxa instantânea de crescimento máximo (SOUZA, 1998). Para as análises estatísticas, foi utilizado o software SAEG (SAEG, 2007).

Na Tabela 1, verifica-se que a utilização de porta-enxertos com maior diâmetro possibilitou maior pegamento de enxertos, independentemente da modalidade de enxertia. Quanto ao método de enxertia, a garfagem à inglesa simples apresentou-se superior à garfagem em fenda cheia, mesmo quando submetido a menor diâmetro de porta-enxertos. Esses resultados corroboram os encontrados por Espíndola et al. (2004), que avaliaram dois intervalos de diâmetro (04-06 $\mathrm{mm}$ e 07-09 $\mathrm{mm}$ ) e dois métodos de enxertia (garfagem à inglesa simples e garfagem em fenda cheia), concluindo que o método mais indicado para enxertia em umbuzeiro é a garfagem à inglês simples sob porta-enxertos de maior diâmetro, por esse ter apresentado melhor performance no número de enxertos pegos e no desenvolvimento da planta enxertada. Porém, discordam dos encontrados por Araújo e Castro Neto (2002), que obtiveram maior percentual de pegamento pelo método de garfagem em fenda cheia $(97,1 \%)$. Os índices de pegamento 
de enxertia superaram os obtidos por Pedrosa et al. (1991), que foram de 33\% e 30\% para os métodos de garfagem à inglês simples e fenda cheia, respectivamente. Hartmann et al. (1990) evidenciam a diferença entre espécies e cultivares quanto ao pegamento nos diversos métodos de enxertia, e que a variação está relacionada com a habilidade de produzir calo a partir de parênquima, essencial para o sucesso da união. Provavelmente, a menor área de corte da garfagem a inglês simples, em relação ao duplo bisel realizado na outra modalidade de enxertia, tenha favorecido maior rapidez na formação de calo e conexão vascular.

Os métodos de garfagem não diferiram estatisticamente entre si quanto ao comprimento das brotações. $\mathrm{O}$ aumento do comprimento das brotações dos enxertos no tempo mostra-se mais evidente nos tratamentos com maior diâmetro de estacas $(0,75$ a $1,0 \mathrm{~cm}$ ), cuja expressão máxima (parâmetro a) foi obtida no inglês simples $(9,92 \mathrm{~cm})$ e na fenda cheia $(11,35 \mathrm{~cm})$ (Figura 1). Souza (2007), em estudo análogo com cajazeira, verificou que apenas aos 90 dias após a enxertia houve diferenças significativas entre as modalidades de enxertia, com a enxertia em garfagem lateral apresentando o menor crescimento $(3,17 \mathrm{~cm})$, e a garfagem em fenda cheia apresentado o maior comprimento $(5,29 \mathrm{~cm})$.
Para o diâmetro das brotações dos enxertos (Figura 2), observou-se comportamento semelhante ao descrito para a variável comprimento das brotações, com a expressão máxima do diâmetro obtida nas mudas enxertadas com maior diâmetros de estacas, na modalidade inglês simples $(0,25 \mathrm{~cm})$ e fenda cheia $(0,23 \mathrm{~cm})$. Esse comportamento pode ser decorrente desses possuírem maior quantitativo de reservas, o que pode ter favorecido a rápida desdiferenciação e rediferenciação celular, com consequente formação de calo e conexão vascular. Esses resultados corroboram os obtidos por Souza (2007), que verificou não haver diferença estatística entre as modalidades de enxertia para a cajazeira, porém com efeito significativo entre os períodos de avaliação. Entretanto, diferem de Espindola et al. (2004), que verificaram maior crescimento das brotações em enxertos de umbuzeiro realizados pelo método de garfagem à inglesa simples.

O método de garfagem à inglesa simples mostrou pegamento de enxertos superior à garfagem em fenda cheia. O maior diâmetro de porta-enxerto possibilitou maior percentual de pegamento da enxertia e maior comprimento e diâmetro das brotações dos enxertos de umbuzeiro.

TABELA 1 - Percentual de pegamento de enxertia em função do diâmetro de porta-enxertos e dos métodos de enxertia de umbuzeiro. Areia-PB, 2009

\begin{tabular}{ccc} 
& \multicolumn{2}{c}{ Diâmetro } \\
\cline { 2 - 3 } Métodos de Enxetia & $\mathbf{0 , 5 - 0 , 7} \mathbf{~ c m}$ & $\mathbf{0 , 7 5 - 1 , 0 ~ c m}$ \\
\hline Inglês Simples & $80 \% \mathrm{aB}$ & $100 \% \mathrm{aA}$ \\
Fenda Cheia & $20 \% \mathrm{bB}$ & $87,5 \% \mathrm{bA}$ \\
\hline
\end{tabular}

Médias seguidas de letras maiúsculas nas linhas e minúsculas nas colunas não diferem significativamente entre si, pelo teste $\mathrm{F}$, a 5\% de probabilidade. 

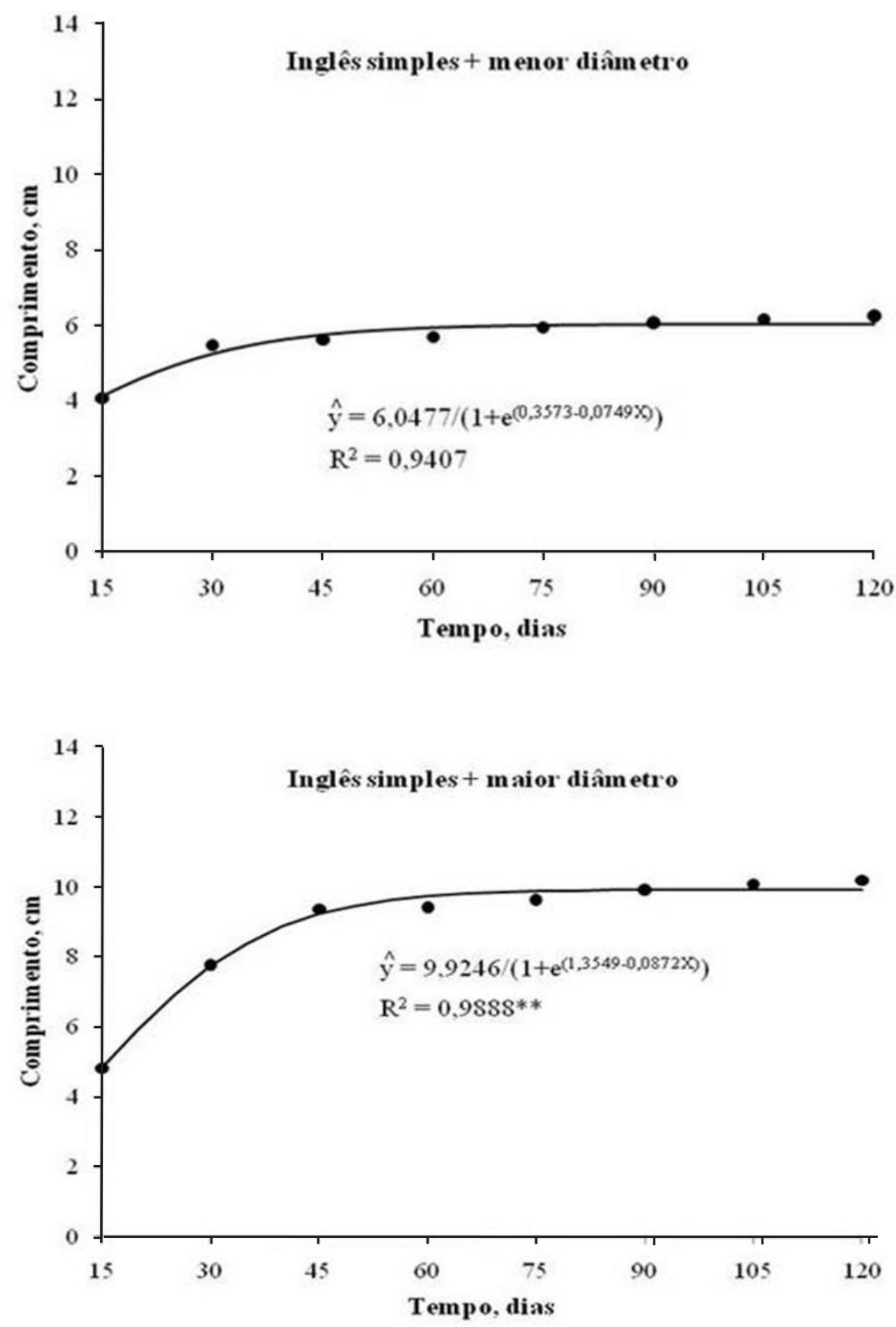

continua 
continuação
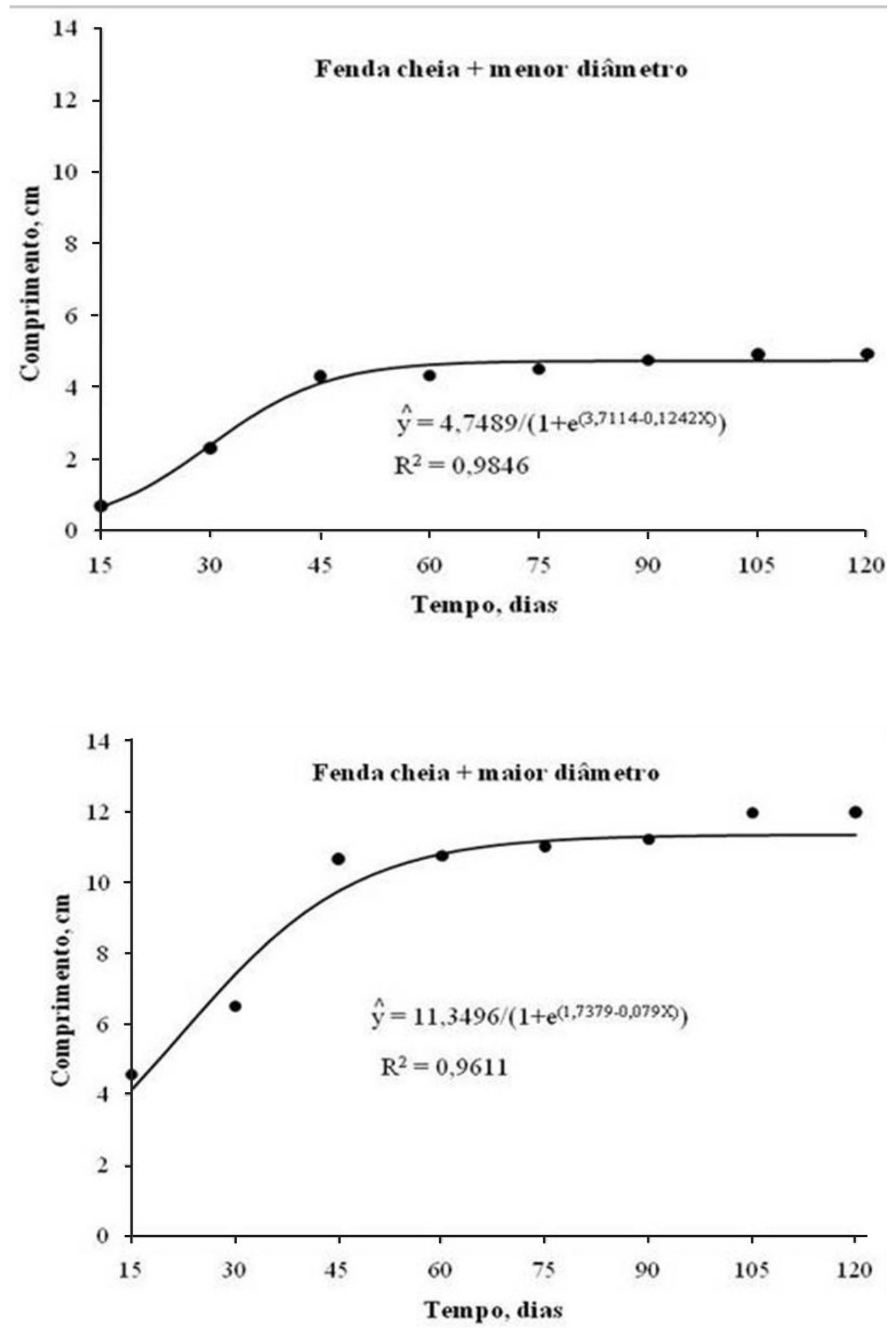

FIGURA 1 - Comprimento de brotações de enxertos de umbuzeiro sob dois métodos de garfagem (inglês simples e fenda cheia) e dois diâmetros de porta-enxerto $(0,5$ a $0,7 \mathrm{~cm}$ e 0,75 a $1,0 \mathrm{~cm})$, em função dos períodos de avaliação. Areia-PB, 2009. 

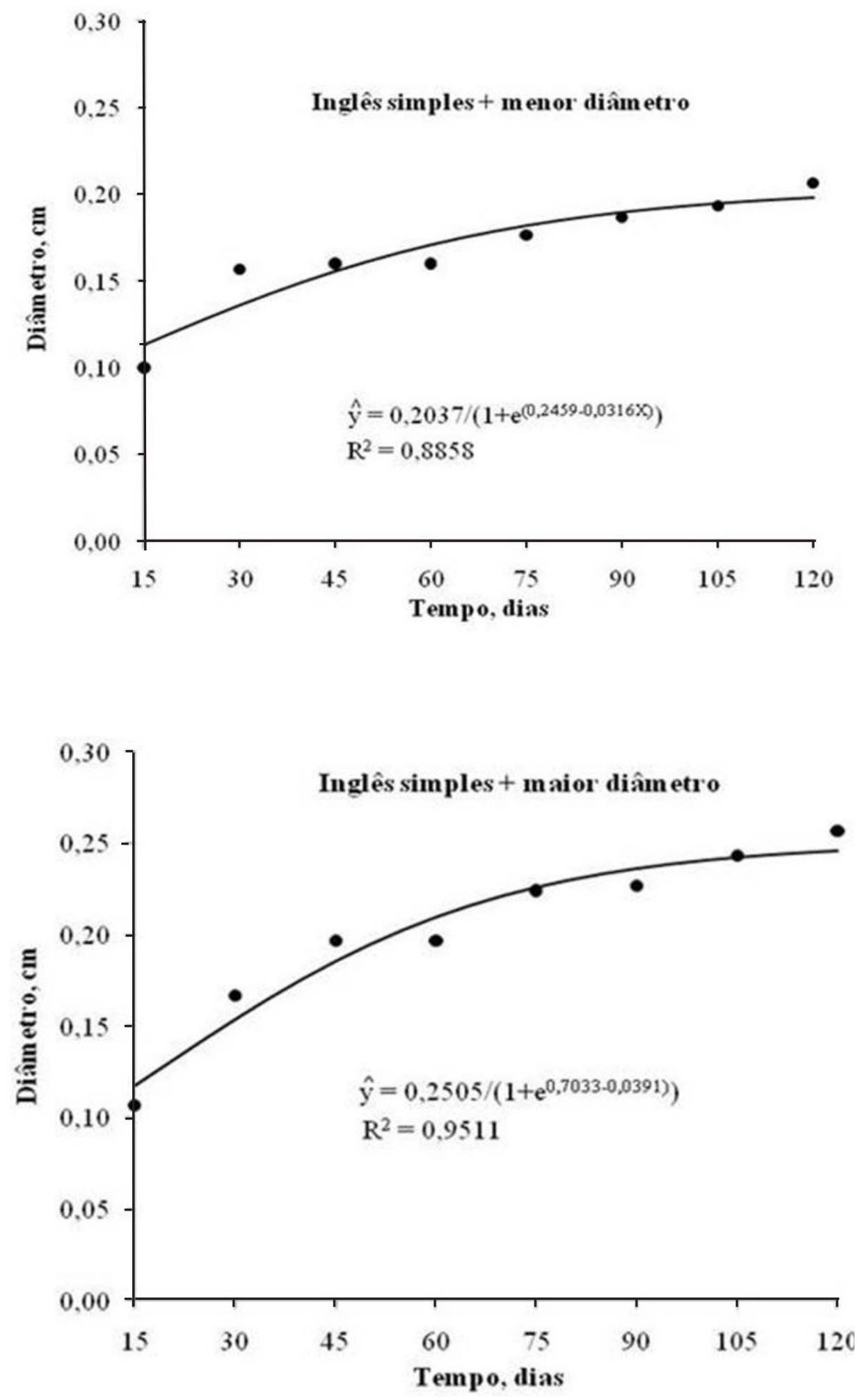
continuação
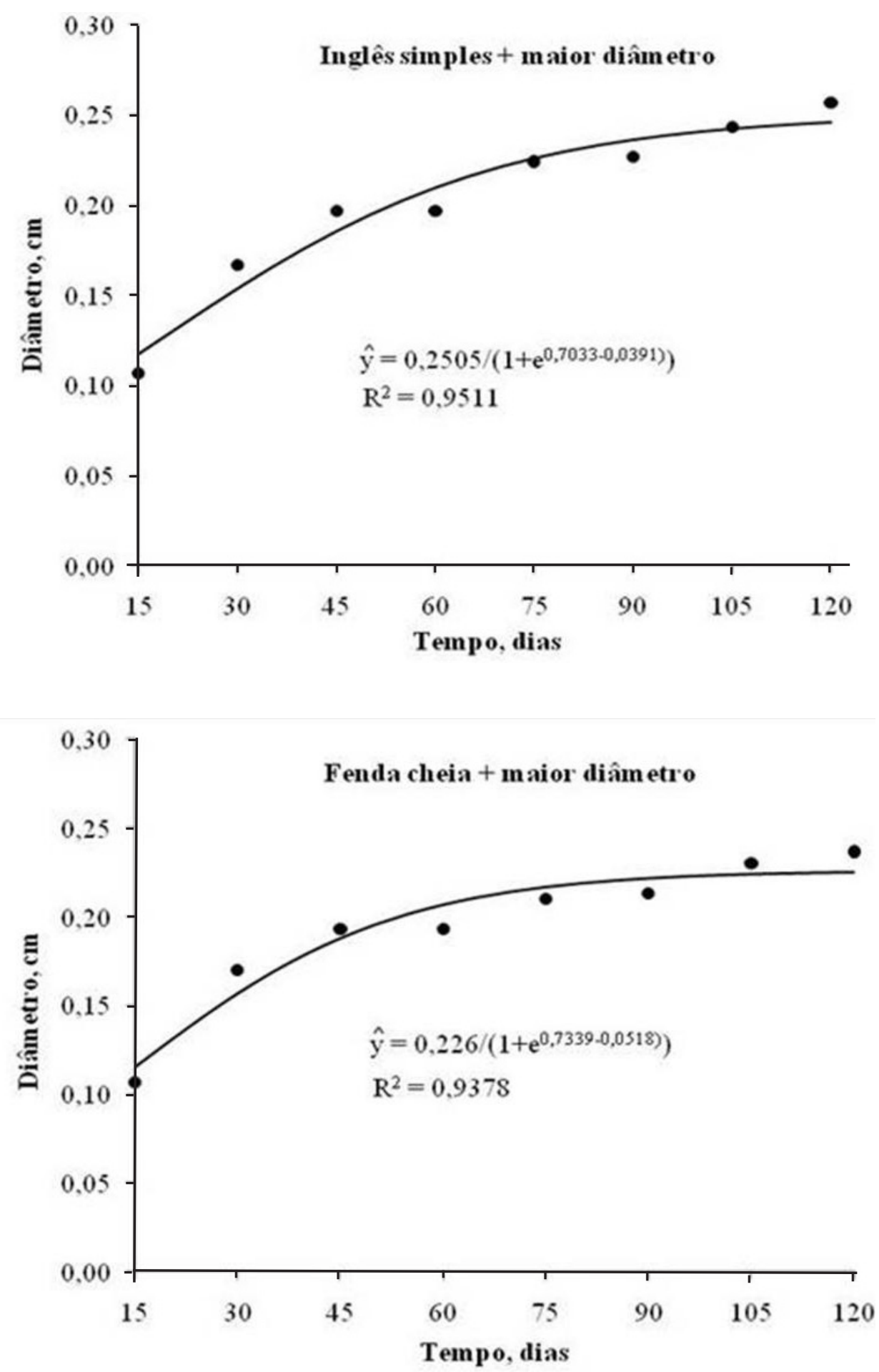

FIGURA 2 - Diâmetro de brotações de enxertos de umbuzeiro sob dois métodos de garfagem (inglês simples e fenda cheia) e dois diâmetros de porta-enxerto $(0,5$ a $0,7 \mathrm{~cm}$ e 0,75 a $1,0 \mathrm{~cm})$, em função dos períodos de avaliação. Areia-PB, 2009. 


\section{REFERENNCIAS}

ARAÚJO, F. P.; CASTRO NETO, M. T. Influência de fatores fisiológicos de plantas-matrizes e de épocas do ano no pegamento de diferentes métodos de enxertia do umbuzeiro. Revista Brasileira de Fruticultura, Jaboticabal, v. 24, n. 3, p. 752-755, 2002.

CODEVASF. Censo frutícola 2001: programa fruticultura, relatório das fases produtivas. Disponível em: <http://www.codevasf.gov.br/fruticultura/>. Acesso em: 21 nov. 2002.

ESPÍNDOLA, A. C. M.; ALMEIDA, C. C. S.; CARVALHO, N. S. G.; ROZA, M. L. A. Diâmetro do caule e método de enxertia na formação de mudas de umbuzeiro (Spondias tuberosa Arr. Cam.). Revista Brasileira de Agrociência, Pelotas, v.10, n. 3, p. 371-372, 2004.

HARTMANN, H. T.; KESTER, D. E.; DAVIES JUNIOR, F. T. Plant propagation: principles and practices. 5. ed. Englewood Cliffs: Prentice-Hall, 1990. 647p.

KHAN, A. S. et al. Estudo de mercado de polpa de frutas produzidas na região sudeste da Bahia. Revista Econômica do Nordeste, Fortaleza, v. 34, n. 2, p. 308-327, 2003.
MARTINS, S.T.; MELO, B. Spondias: cajá e outras. Disponível em: <http://www.todafruta.com.br>. Acesso em: 06 fev. 2007.

PEDROSA, A. C.; LEDERMAN, I. E.; BEZERRA, J. E. F; DANTAS, A. P.; GONZAGA NETO, L. Métodos de enxertia do umbuzeiro (Spondias tuberosa Arr. Cam) em viveiro. Revista Brasileira de Fruticultura, Jaboticabal, v. 13, n. 1, p. 59-62, 1991.

PIRES, M. G. M. Estudo taxonômico e área de ocorrência de Spondias tuberosa Arr. Câm. (umbuzeiro) no Estado de Pernambuco, Brasil. 1990. 290 f. Dissertação (Mestrado em Botânica) - Universidade Federal Rural de Pernambuco, Recife, 1990.

SAEG. Sistema para análises estatísticas, versão 7.1. Viçosa, MG: Fundação Arthur Bernardes, 1997.

SOUZA, E. P. Propagação da cajazeira e do umbuzeiro por meio de estaquia, alporquia e enxertia. 2007. 87 f. Dissertação. (Mestrado em Agronomia) - Centro de Ciências Agrárias, Universidade Federal da Paraíba, João Pessoa. 2007.

SOUZA, G. da S. Introdução aos modelos de regressão linear e não linear. Brasília: EmbrapaSPI/SEA, 1998. 505p. 